\title{
Ectopic Cushing's syndrome secondary to olfactory neuroblastoma
}

\author{
Kenny $\mathrm{Yu}^{1}$ (D) $\cdot$ Federico Roncaroli ${ }^{2} \cdot$ Tara Kearney $^{3} \cdot$ David Ewins $^{4} \cdot$ Deepa Beeharry $^{4} \cdot$ Thomas Naylor $^{4} \cdot$ David Ray $^{3}$. \\ Rajiv Bhalla ${ }^{5}$ Kanna Gnanalingham ${ }^{1}$
}

Received: 9 October 2017 / Accepted: 21 December 2017 / Published online: 17 January 2018

(C) The Author(s) 2018. This article is an open access publication

\begin{abstract}
We present the case of a patient with Cushing's syndrome secondary to ectopic ACTH secretion. A MR of the head showed a leftsided nasal mass extending down from the cribriform plate. The patient underwent endoscopic resection with nearly complete removal of the mass. Histological examination showed an ACTH-secreting olfactory neuroblastoma (ONB). The patient's cortisol levels returned to normal range after surgery and have remained normal for over a year. ONB is a rare cause for ectopic ACTH secretion. This case highlights the diagnostic and management difficulties in patients with ectopic ACTH secretion, and provides a brief review of ONB.
\end{abstract}

Keywords Olfactory neuroblastoma $\cdot$ Ectopic $\cdot$ ACTH $\cdot$ Cushing's

\section{Case presentation}

A previously healthy 55-year-old gentleman presented with a 1 -year history of progressive sore throat, post nasal drip, excessive fatigue, generalised muscle weakness and reduced exercise tolerance. He had noted increased truncal weight gain and difficulty climbing stairs, culminating in a fall and hospitalisation.

On examination, he had truncal obesity, poor skin healing, bruising around venepuncture sites, bilateral pitting oedema up to the sacrum and signs of proximal myopathy. His blood

Kenny Yu

Kenny.yu@srft.nhs.uk

1 Department of Neurosurgery, Salford Royal NHS Foundation Trust, Manchester Academic Health Science Centre, Salford M6 8HD, UK

2 Division of Neuroscience and Experimental Psychology, Faculty of Biology, Medicine and Health, School of Biological Science, University of Manchester, Manchester M13 9PT, UK

3 Department of Endocrinology, Salford Royal NHS Foundation Trust, Manchester Academic Health Science Centre, Salford M6 8HD, UK

4 Department of Endocrinology, Countess of Chester Hospital, Liverpool Road, Chester CH2 1UL, UK

5 Department of Otorhinolaryngology, Salford Royal NHS Foundation Trust, Manchester Academic Health Science Centre, Salford M6 $8 \mathrm{HD}, \mathrm{UK}$ pressure on admission was elevated at $180 / 95 \mathrm{~mm} / \mathrm{Hg}$. He had intermittent episodes of confusion and was noted to have lost his sense of smell and taste.

Investigations revealed marked hypokalaemic alkalosis that was initially resistant to treatment with enalapril, spironolactone and Sando-K (serum potassium $2.5 \mathrm{mmol} / \mathrm{l}$ [normal range 3.5$5.0 \mathrm{mmol} / \mathrm{l}$ ], serum bicarbonate $45 \mathrm{mmol} / 1$ [normal range 20 $32 \mathrm{mmol} / \mathrm{l}]$ ). Although not previously known to be diabetic (HbAlc 3 months prior to admission was just $45 \mathrm{mmol} / \mathrm{mol}$ ), a random blood glucose on admission was elevated at $28.6 \mathrm{mmol} / \mathrm{l}$ and his $\mathrm{HbAlc}$ was $71 \mathrm{mmol} / \mathrm{mol}$, confirming recent onset diabetes. As he was symptomatic with thirst and polyuria, he was started on Humulin I insulin (20 units b.d.).

A diagnosis of Cushing's syndrome was made and in view of the rapid onset of symptoms with marked metabolic features and fluid retention, the possibility of ectopic ACTH was entertained.

Random cortisol (2213 nmol/l), adrenocorticotrophic hormone (ACTH) $(40 \mathrm{pmol} / \mathrm{l})$ and $24-\mathrm{h}$ urine free cortisol $(18,091 \mathrm{nmol} / 24 \mathrm{~h})$ levels were significantly elevated [normal ranges $<607 \mathrm{nmol} / \mathrm{l}, 2-11 \mathrm{pmol} / 1$ and $<165 \mathrm{nmol} / 24 \mathrm{~h}$, respectively]. A subsequent dexamethasone suppression test failed to demonstrate adequate suppression on low dose (cortisol $1562 \mathrm{nmol} / \mathrm{l}$, ACTH $76 \mathrm{pmol} / \mathrm{l}$ ) or high dose dexamethasone (cortisol $1625 \mathrm{nmol} / \mathrm{l}$, ACTH $59 \mathrm{pmol} / \mathrm{l}$ ). These results confirmed ACTH-dependent Cushing's syndrome.

MR scan of brain revealed a normal pituitary gland (Fig. 1a, solid arrow), with no asymmetry in contrast 
Fig. 1 Sagittal T1-weighted MRI with gadolinium contrast (a) and Coronal T2-weighted MRI (b) revealing an enhancing nasal mass extending down from the cribriform plate of the anterior cranial fossa (open arrow), with the presence of a normal pituitary gland (solid arrow)
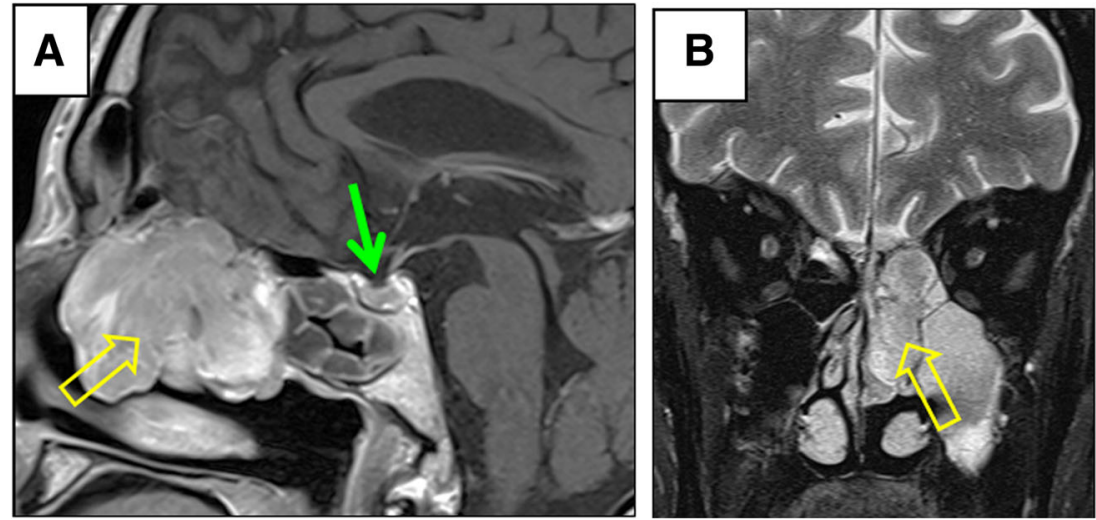

enhancement. However, the scan also revealed a left-sided nasal mass (Fig. 1a, open arrow) extending down from the cribriform plate and involving the ethmoid sinuses and the ipsilateral turbinates. The lesion spanned from the back of frontal sinus to just anterior to the sphenoid sinus.

Whole body CT scan revealed bilateral nodular hyperplasia of the adrenal glands and no other mass lesions and the patient underwent a diagnostic endoscopic biopsy.

Subsequent testing revealed a high ACTH precursor concentration of $613 \mathrm{pmol} / \mathrm{l}$ [normal range $0-40 \mathrm{pmol} / \mathrm{l}]$ suggestive of an ectopic source of ACTH [4].

Medical management of the ectopic ACTH syndrome proved difficult with maximally tolerated doses of metyrapone (750 mg t.d.s.) and it was only after the addition of ketoconazole ( $800 \mathrm{mg}$ daily t.d.s) that his general health and cortisol profile (474-599 nmol/1) improved sufficiently to allow surgery.

The patient underwent endoscopic resection via an endonasal approach, with a right naso-septal flap hinged on the sphenopalatine pedicle for subsequent repair. A moderately soft and avascular left-sided nasal tumour arising from the cribriform plate was resected in piecemeal fashion. The adjacent cribriform plate was partly eroded; however, the overlying dura mater was intact. All abnormal tissue down to the cribriform plate was resected, with diathermy of the anterior skull base dura, which was left largely in situ to minimise the risk of post-op CSF leak. Nasal septal flap was then used to cover the anterior skull base dura, supported with fibrinogen sealant (i.e., Tisseel, Baxter, UK), Nasopore (Stryker, UK) and a Foley balloon catheter for 7 days.

Tissue from the initial transnasal biopsy and from endoscopic resection showed respiratory-type mucosa and bone infiltrated by a tumour composed of sheets and merging lobules. Lobules were delimited by fibro-vascular connective tissue. Neoplastic cells had scanty cytoplasm and moderately atypical nucleus with fine, salt and pepper chromatin and small nucleolus. Mitoses were rare (average $2 \times 10$ high power fields at $\times 40$ magnification). Necrosis was absent. A few
Homer-Wright pseudo-rosettes were present. Tumour cells were intensely and uniformly positive for neuron specific enolase and synaptophysin. Chromogranin A was focally expressed immunostains for cytokeratin 7 , cytokeratin 20 , cytokeratin CAM5.2 were negative. The immunostain for S100 protein revealed a meshwork of sustentacular cells and the immunoreaction for neurofilament proteins documented focal neuropil. No obvious neuronal differentiation was noted. Immunostains for pituitary hormones showed ACTH expression in several neoplastic cells but neoplastic cells did not express the transcription factor T-pit (courtesy Dr. Olivera Casar-Borotra, Clinical Uppsala University Hospital Uppsala, Sweden) (Fig. 2). Pathological features were consistent with low-grade (Hyams' grade II) olfactory neuroblastoma (ONB) with ectopic ACTH. About $2 \%$ of neoplastic cells were positive for Ki-67. Absence of cytokeratin CAM5.2 expression, the presence of sustentacular cells, focal expression of neurofilament protein and the absence of T-pit expression excluded the possibility of an ectopic corticotroph adenoma.

Post-operative recovery was slow. There was rapid normalisation of serum glucose and blood pressure. Antihypertensive medications, insulin, metyrapone and ketoconazole were withdrawn. This coincided with improvement in his early morning cortisol levels, without steroid replacement. An overnight dexamethasone suppression test at 4 weeks following surgery revealed an adequate suppression of early morning cortisol to $14 \mathrm{nmol} / \mathrm{l}$, consistent with remission of his Cushing's syndrome. The patient proceeded to have adjuvant radiotherapy to the post resection cavity and remains in remission at 1-year follow-up.

\section{Discussion}

Cushing's disease secondary to ACTH-secreting pituitary adenoma is the most common cause of Cushing's syndrome. Other causes include iatrogenic steroids and adrenal adenomas. Ectopic secretion of ACTH accounts for about 10-15\% 

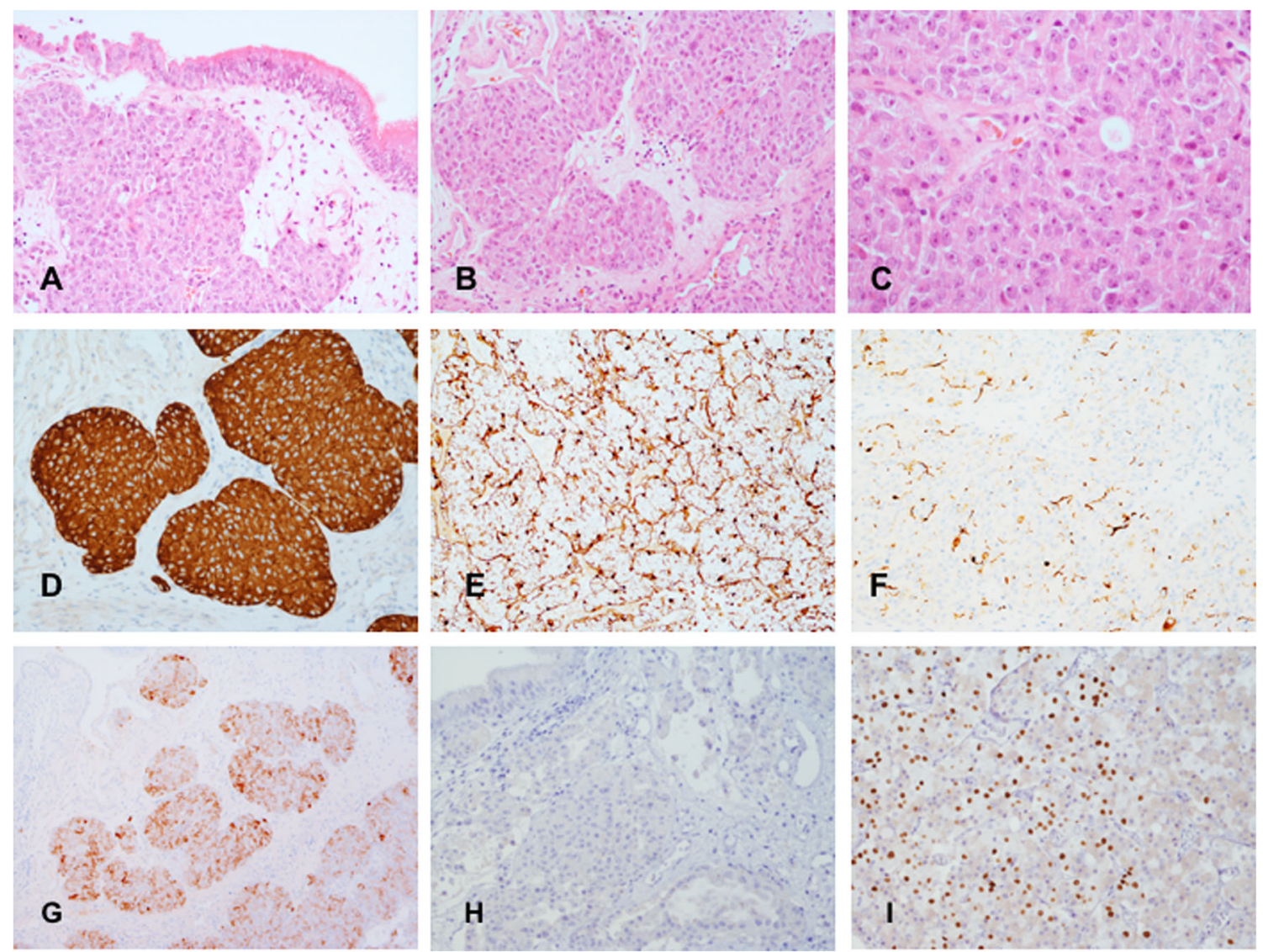

Fig. 2 Nasal mucosa appears to be infiltrated by tumour (a haematoxylin and eosin, $\times 10)$; the lesion has lobular and sheet-like architecture (b haematoxylin-eosin, $\times 10$ ) and consists of moderately atypical cells with scanty cytoplasm $(\mathbf{c}$ haematoxylin-eosin, $\times 20)$. Neoplastic cells are intensely positive for synaptophysin (d immunoperoxidase, $\times 10$ ); the immunoreaction for S-100 protein highlights sustentacular cells (e

of cases of hypercortisolism [5] and it is usually associated with lung and pancreatic neuroendocrine tumours.

Ectopic ACTH was suspected in this case due to the rapid onset of symptoms and the marked metabolic features, lack of suppression after dexamethasone and normal pituitary at MRI.

ONB accounts for $2-3 \%$ of tumours of the nasal cavity and it is likely derived from the olfactory basal reserve cells in the olfactory mucosa [1]. ONB occurs in a wide range of ages and frequently presents with nasal obstruction, epistaxis and anosmia [7]. The prognosis of ONB is variable with 10-year survival rates between 45 and $76 \%$ [6]. Adjuvant radiotherapy for the primary lesion site was given in this case to reduce the risk of local recurrence [8]. Long-term follow-up of these patients is recommended. Rarely ONB can cause a paraneoplastic syndrome that is secondary to ectopic secretion of peptides and hormones, or an immune response due to cross-reactivity between neoplastic cells and normal tissues [3]. Endocrinological manifestations of ONB include syndrome of inappropriate ADH secretion, ectopic ACTH syndrome, humoral hypercalcemia of malignancy, hypertension caused by immunoperoxidase, $\times 20$ ); the present of focal neuropil is shown with the immunoreaction for neurofilament proteins ( $\mathbf{f}$ immunoperoxidase, $\times 20)$; several tumour cells are positive for ACTH (g immunoperoxidase, $\times 4$ ); there is no expression of T-pit (h immunoperoxidase, $\times 20$ ); normal adenohypophysis used as control shows normal T-pit expression (i immunoperoxidase, $\times 20$ )

catecholamine secretion and hyperprolactinemia [2]. Only four cases with ACTH secretion confirmed at immunohistochemistry on tissue have previously been reported [1].

Identifying the source of ACTH in ACTH-dependent Cushing's syndrome can be challenging. The MR scan of the pituitary, even with dynamic contrast enhancement does not always reveal an adenoma [3]. In such cases, CT scan of body (for ectopic source) and inferior petrosal venous sinus sampling (IPSS) may help in the localisation of ACTH source [3]. The presence of high levels of ACTH precursor molecules can also suggest an ectopic source of ACTH [4]. However, in the present case, the proximity of ONB to the pituitary gland and the potential sharing of venous drainage may have led to false positive results with IPSS. Hence, surgical biopsy of the nasal lesion was helpful in the diagnosis and guided subsequent treatment. Although surgical resection of the primary ACTH-producing lesion can normalise cortisol levels, surgical cure in rare.

The present case highlights some of the diagnostic challenges in isolating the source of ACTH production and the surgical management of the condition. 
Authors' contributions KY was directly involved in the patient's care and drafted the manuscript.

FR was involved in the patient's diagnosis, revised the manuscript and added the pathological description.

TK was directly involved in the patient's care and reviewed the manuscript.

DE was directly involved in the patient's care and revised the manuscript.

DB and TN were directly involved in the patient's care and reviewed the manuscript.

DR revised and reviewed and manuscript.

RB was directly involved in the patient's care and reviewed the manuscript.

$\mathrm{KG}$ was directly involved in the patient's care and revised the manuscript.

\section{Compliance with ethical standards}

Conflict of interests The authors declare that they have no conflict of interest.

Informed consent The patient has consented to the submission of this case report to the journal.

Open Access This article is distributed under the terms of the Creative Commons Attribution 4.0 International License (http:// creativecommons.org/licenses/by/4.0/), which permits unrestricted use, distribution, and reproduction in any medium, provided you give appropriate credit to the original author(s) and the source, provide a link to the Creative Commons license, and indicate if changes were made.

\section{References}

1. Koo BK, An JH, Jeon KH, Choi SH, Cho YM, Jang HC, Chung JH, Lee CH, Lim S (2008) Two cases of ectopic adrenocorticotropic hormone syndrome with olfactory neuroblastoma and literature review. Endocr J 55:469-475
2. Kunc M, Gabrych A, Czapiewski P, Sworczak K (2015) Paraneoplastic syndromes in olfactory neuroblastoma. Contemp Oncol (Pozn) 19:6-16. https://doi.org/10.5114/wo.2015.46283

3. Lacroix A, Feelders RA, Stratakis CA, Nieman LK (2015) Cushing's syndrome. Lancet 386:913-927. https://doi.org/10.1016/S01406736(14)61375-1

4. Monaghan PJ, Kyriacou A, Sturgeon C, Davies A, Trainer PJ, White A, Higham CE (2016) Proopiomelanocortin interference in the measurement of adrenocorticotrophic hormone: a United Kingdom National External Quality Assessment Service study. Clin Endocrinol 85:569-574. https://doi.org/10.1111/cen.13118

5. Oldfield EH, Doppman JL, Nieman LK, Chrousos GP, Miller DL, Katz DA, Cutler GB Jr, Loriaux DL (1991) Petrosal sinus sampling with and without corticotropin-releasing hormone for the differential diagnosis of Cushing's syndrome. N Engl J Med 325:897-905. https://doi.org/10.1056/NEJM199109263251301

6. Rimmer J, Lund VJ, Beale T, Wei WI, Howard D (2014) Olfactory neuroblastoma: a 35-year experience and suggested follow-up protocol. Laryngoscope 124:1542-1549. https://doi.org/10.1002/lary. 24562

7. Shah K, Perez-Ordonez B (2016) Neuroendocrine neoplasms of the sinonasal tract: neuroendocrine carcinomas and olfactory neuroblastoma. Head Neck Pathol 10:85-94. https://doi.org/10.1007/s12105016-0696-7

8. Ward PD, Heth JA, Thompson BG, Marentette LJ (2009) Esthesioneuroblastoma: results and outcomes of a single institution's experience. Skull Base 19:133-140. https://doi.org/10.1055/s-00281096195 